Article

\title{
Synthesis, characterisation and activity of SBA-16 supported oxidation catalysts for $\mathrm{CO}$ conversion
}

\author{
N. K. Renuka ${ }^{a, *}$, K. Anas ${ }^{b}$, C. U. Aniz ${ }^{b}$ \\ a Department of Chemistry, University of Calicut, Kerala-673 635, India \\ ${ }^{\mathrm{b}} R \& D$ Division, Sud-Chemie India Pvt. Limited, Binanipuram-683502, Kerala, India
}

A R T I C L E I N F O

Article history:

Accepted 13 May 2015

Published 20 August 2015

Keywords:

Rice husk ash

Mesoporous silica

SBA-16

Metal oxide catalyst

Carbon monoxide oxidation
Received 20 March 2015

A B S T R A C T

$\mathrm{V}_{2} \mathrm{O}_{5}, \mathrm{CeO}_{2}$, and $\mathrm{CuO}$ were dispersed on rice husk derived SBA-16, and the $\mathrm{CO}$ oxidation activities of these systems were examined. The catalysts were characterised using X-ray diffraction, scanning electron microscopy, transmission electron microscopy, temperature-programmed reduction, and diffuse reflectance ultraviolet spectroscopy. The $\mathrm{CuO}$ doped mesoporous silica was identified as a promising catalyst. More than $98 \%$ of CO conversion was achieved over the system.

(C) 2015, Dalian Institute of Chemical Physics, Chinese Academy of Sciences. Published by Elsevier B.V. All rights reserved.

\section{Introduction}

The catalytic oxidation of $\mathrm{CO}$ has attracted great attention because of its extensive applications in various fields including automotive emission control, CO preferential oxidation for proton exchange membrane fuel cells, exhaust abatement for $\mathrm{CO}_{2}$ lasers and trace $\mathrm{CO}$ removal. Most of the catalysts explored to this effect include supported precious metals such as Pt, Pd and $\mathrm{Au}$ on various oxides [1-7]. However, these catalysts have the drawback of high cost. Hence ongoing search is there for more economic solid oxide materials that effectively catalyse CO oxidation. However, pure metal oxides are not attractive because of their poor thermal stability, which necessitates the presence of suitable supports for fine dispersion. The presence of a support enhances the stability and effective surface access of the reactants. Mesoporous metal oxides are promising support materials because of their high surface area and porosity characteristics. Among these, mesoporous $\mathrm{SiO}_{2}$ has been extensively used as a support in various reactions of industrial and environmental significance.

This study provides the first account of a rice husk derived SBA-16 supported metal oxide $\left(\mathrm{V}_{2} \mathrm{O}_{5}, \mathrm{CeO}_{2}\right.$, or $\left.\mathrm{CuO}\right)$ catalysts for CO oxidation. Mesoporous silica materials of the SBA type (Santa Barbara acid) exhibit large pore sizes (2-30 nm), thick pore walls and high stability. Among the SBA materials, SBA-16 has attracted much attention because the 3D cubic arrangement of mesopores allows a favourable mass transfer of bulky reactants. Usually, strong acidic conditions are widely used for the synthesis of SBA-16. But the use of strong acid in the synthesis causes problems such as high cost of reagents, complex post-treatment process and waste disposition. In the present study, SBA-16 is achieved from rice husk derived silica under mild reaction conditions. The objective of this study is to use the tailored pore size of SBA-16, which will positively tune the activity of dispersed oxidation catalysts towards CO conversion. The catalysts are characterised using low- and wide-angle X-ray diffraction (XRD), scanning electron microscopy (SEM), transmission electron microscopy (TEM), temperature-pro- 
grammed reduction (TPR), surface area analysis and porosity studies.

\section{Experimental}

\subsection{Synthesis and characterisation of catalysts}

Rice husk derived SBA-16 was prepared as follows. Rice husk was washed to remove the impurities, followed by digestion with $10 \% \mathrm{HCl}$ for $3 \mathrm{~h}$. The residue was washed thoroughly and dried at $110{ }^{\circ} \mathrm{C}$ for $12 \mathrm{~h}$. Calcination of the solid at $600{ }^{\circ} \mathrm{C}$ for $6 \mathrm{~h}$ yielded silica, which served as the precursor for SBA-16. To achieve SBA-16, the silica was added to $\mathrm{NaOH}$ (E-Merck, Darmstadt, Germany) solution and stirred for $3 \mathrm{~h}$, followed by the addition of an aqueous solution of cetrimonium bromide (CTAB; Sigma-Aldrich, St. Louis, MO, USA). Molar ratio of $\mathrm{SiO}_{2}: \mathrm{NaOH}: \mathrm{CTAB}: \mathrm{H}_{2} \mathrm{O}$ was maintained as $4: 2: 1: 277$, and the final $\mathrm{pH}$ of the solution was adjusted to $\sim 11$. Stirring for $48 \mathrm{~h}$ under room temperature led to the precipitation of the final material, which was washed thoroughly with an ethanol and water mixture. The solid was filtered and calcined at $600{ }^{\circ} \mathrm{C}$ for $5 \mathrm{~h}$. The active metal oxide loading was fixed as $10 \mathrm{wt} \%$ of the silica in the supported system. Wet impregnation procedure using ammonium metavanadate was used to yield the $\mathrm{V}_{2} \mathrm{O}_{5}$ /SBA-16 catalyst. $\mathrm{CeO}_{2}$ - and $\mathrm{CuO}$-loaded silica catalysts were synthesised via deposition precipitation using ammonia from their respective nitrate solutions.

The microstructure of the samples was investigated using a Philips CM200 TEM (Amsterdam, The Netherlands) and a JEOL JSM-848 SEM instrument (Tokyo, Japan). Powder XRD patterns of the samples were recorded on a Rigaku D/MAX diffractometer (Tokyo, Japan) using $\mathrm{Cu} K_{\alpha}$ radiation. Low angle XRD was achieved using a Bruker Nanostar instrument (Karlsruhe, Germany). Porosity and BET surface area were obtained on a Micromeritics Gemini surface area analyser (Norcross, GA, USA). Diffuse reflectance ultravoilet (UV) spectra were taken using a Jasco V-550 spectrophotometer (Tokyo, Japan). The TPR studies were performed using $\mathrm{H}_{2}$ on a Micromeritics Pulse Chemisorb-2705 fitted with a thermal conductivity detector.

\subsection{Catalyst testing}

CO oxidation activity was monitored as follows. The catalyst samples were activated at $300{ }^{\circ} \mathrm{C}$ for $1 \mathrm{~h}$ prior to the reaction studies. Activated catalyst samples ( $0.3 \mathrm{~g})$ were supported be- tween porcelain beads in the middle of a quartz reactor. The inlet gas was a calibrated mixture gas of $6 \%(v / v)$ of $\mathrm{O}_{2}, 1 \%$ $(v / v) \mathrm{CO}$ and the rest of $\mathrm{N}_{2}$. The gas flow was adjusted to a space velocity of $28800 \mathrm{~h}^{-1}$. $\mathrm{CO}$ and $\mathrm{CO}_{2}$ in the outlet gas were separated using "Pouropack" packed column followed by conversion to methane by the "methanator", detected separately, and analysed using gas chromatography.

\section{Results and discussion}

\subsection{Characterisation of the support material}

Rice husk was extracted with acid and yielded $20 \% \mathrm{SiO}_{2}$, which corresponded to a silica conversion of $91 \%$ in the ash. Rice husk derived silica particles were $\sim 10 \mathrm{~nm}$ in size, as indicated by the TEM image (Fig. 1(a)). The powder XRD data indicated an amorphous material (Fig. 1(b)). This result was supported by the selected area electron diffraction pattern associated with the TEM image.

The physical characteristic features of SBA-16 derived from rice husk are displayed in Fig. 2. The mesoporous system also showed a significant amorphous nature as indicated by the wide-angle XRD pattern. The TEM image showed well-ordered hexagonal mesopores, which were separated from each other by thick amorphous walls of silica, as is expected for the SBA-16 material. Pores of diameter $\sim 4 \mathrm{~nm}$ are visible in the image. The SEM image of SBA-16 shows interconnected wheat-like species of length $\sim 200 \mathrm{~nm}$ and width $\sim 70 \mathrm{~nm}$. Further confirmation of the mesoporous nature was achieved via $\mathrm{N}_{2}$ adsorption and low angle XRD analysis. The low-angle XRD pattern of mesoporous silica showed diffraction peaks at $d$ spacings $10.77,7.61$, and $6.01 \mathrm{~nm}$ (corresponding to $2 \theta=0.82^{\circ}$, $1.17^{\circ}$, and $1.47^{\circ}$ ) signifying (110), (200), and (211) planes, respectively, showing the cubic body centred space group structure of SBA-16 (Im3m space group). The lattice parameter derived from the diffraction pattern was $15.14 \mathrm{~nm}$. Presence of ink-bottle-type pores, which are characteristic of SBA-16, were indicated in the $\mathrm{N}_{2}$ adsorption profile, which showed type IV isotherm with $\mathrm{H} 1$ type broad hysteresis loop closing around a $p / p_{0}$ of 4.5 [8]. The average mesopore size of the material was $4.2 \mathrm{~nm}$, which agrees with that of TEM analysis. Presence of intra-wall microporosity, another characteristic feature of SBA-16, was also shown in the pore distribution profile, and the micropore volume calculated from the $\alpha$ s-plot was $0.17 \mathrm{~cm}^{3} / \mathrm{g}$. BET surface area and total pore volume were $226 \mathrm{~m}^{2} / \mathrm{g}$ and
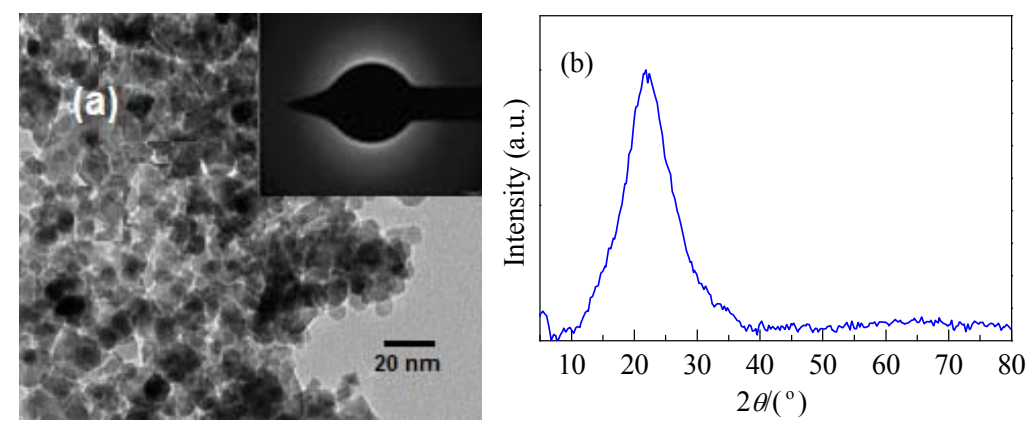

Fig. 1. TEM image (a) and powder XRD pattern (b) of rice husk derived silica. 

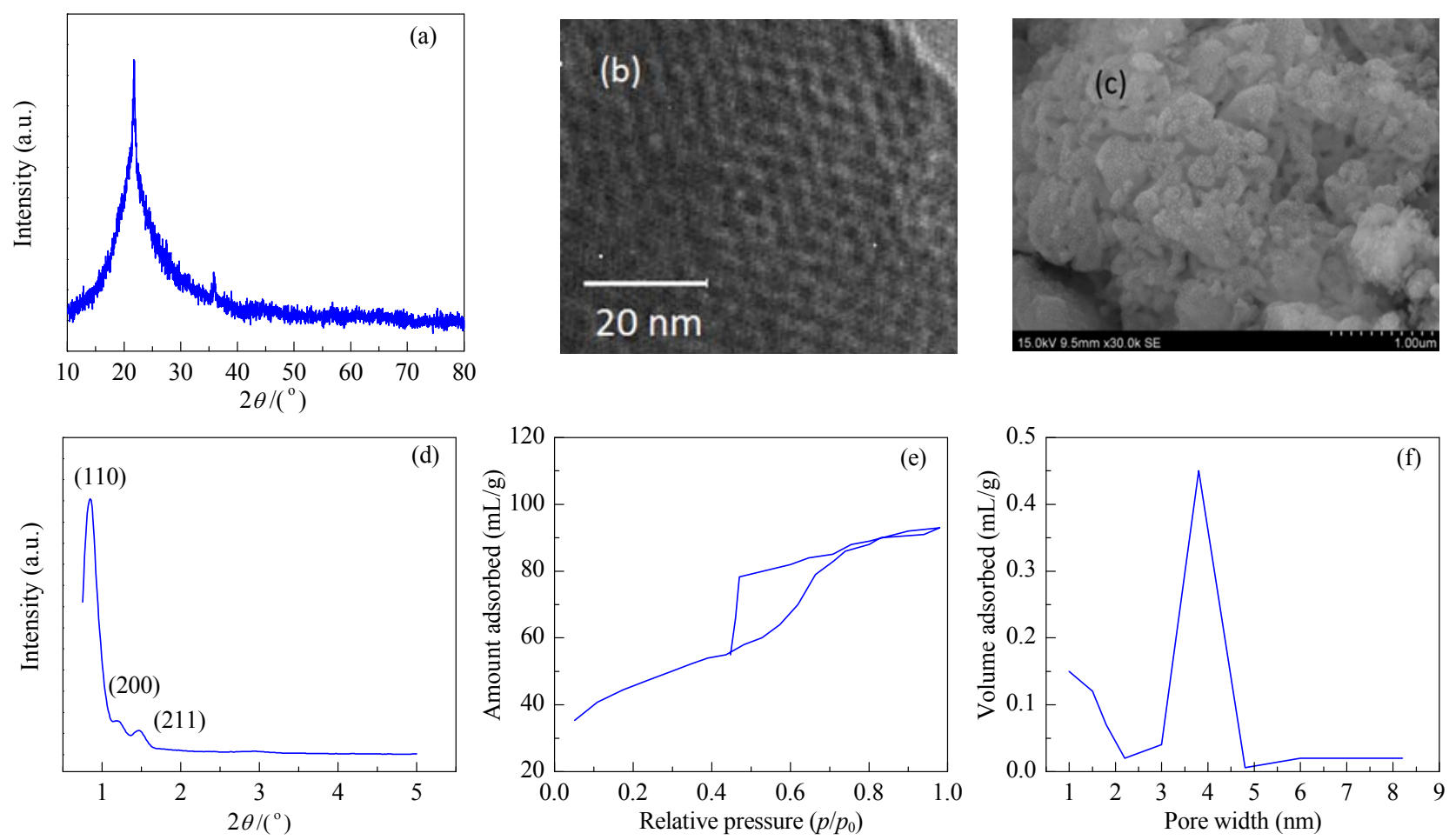

Fig. 2. Wide-angle XRD pattern (a), TEM image (b), SEM image (c), low-angle XRD pattern (d), $\mathrm{N}_{2}$ hysteresis loop (e), and pore distribution (f) of rice husk derived SBA-16.

$0.37 \mathrm{~cm}^{3} / \mathrm{g}$, respectively. Pore wall thickness $(8.9 \mathrm{~nm})$ was calculated using the formula, wall thickness $t=\left(\left(\sqrt{3} a_{0} / 2\right)-d\right)$, with the help of spacing $(d)$ and lattice parameter $\left(a_{0}\right)$.

\subsection{Characterisation of the supported catalysts}

Figure 3 depicts the wide-angle XRD patterns of the catalyst samples. No significant change was noticed in the XRD patterns of $\mathrm{V}_{2} \mathrm{O}_{5}$ /SBA-16 and CuO/SBA-16 when compared with that of mesoporous silica, indicating that the metal oxides are finely dispersed on the support or the crystallites of the metal oxides are too small to be detected by XRD. However, there was a no-

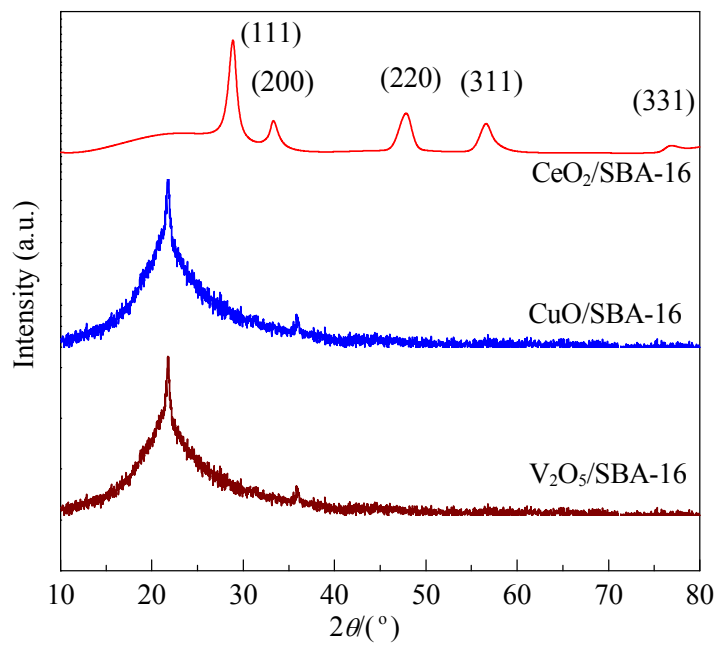

Fig. 3. XRD patterns of metal oxides loaded on SBA-16. table difference in the pattern of the $\mathrm{CeO}_{2}$-based system, where additional peaks appeared, concomitant with an increase of crystallinity. Reflections observed at $2 \theta=28.88^{\circ}, 33.32^{\circ}$, $47.84^{\circ}, 56.6^{\circ}$, and $76.9^{\circ}$, corresponding to $d$ spacings $0.31,0.27$, $0.19,0.16$, and $0.12 \mathrm{~nm}$, signify (111), (200), (220), (311), and (331) planes of $\mathrm{CeO}_{2}$ crystallites (JCPDS 34-0394), respectively. The cubic fluorite-type lattice of ceria is clearly shown by this. The SEM and TEM images (data not shown) of the supported systems differed little from those of pure SBA-16, showing that the impregnation did not affect the morphology of the support. However, a reduction in surface area and other pore characteristics was observed as a result of pore filling because of metal oxide addition (Table 1 ).

The diffuse reflectance UV spectra of the samples were recorded in the range $200-800 \mathrm{~nm}$ (Fig. 4(a)). The pure SBA-16 support showed no signal in the above-mentioned wavelength range. $\mathrm{CeO}_{2} / \mathrm{SBA}-16$, in which crystallite cerium oxide existed, showed three peaks, two prominent peaks at $\sim 250$ and 350 $\mathrm{nm}$, and a comparatively small one at $280 \mathrm{~nm}$. The first peak corresponded to $\mathrm{Ce}^{3+}$ present in the sample arising from $\mathrm{Ce}^{3+} \leftarrow \mathrm{O}^{2-}$, although the XRD results ruled out the possibility of crystalline $\mathrm{Ce}_{2} \mathrm{O}_{3}$. The second peak was an inter-band transi-

Table 1

Physical characteristics of catalysts.

\begin{tabular}{lcccc}
\hline Catalyst & $\begin{array}{c}\text { Band gap } \\
(\mathrm{eV})\end{array}$ & $\begin{array}{c}\text { Surface area } \\
\left(\mathrm{m}^{2} / \mathrm{g}\right)\end{array}$ & $\begin{array}{c}\text { Pore volume } \\
\left(\mathrm{cm}^{3} / \mathrm{g}\right)\end{array}$ & $\begin{array}{c}\text { Average pore } \\
\text { width }(\mathrm{nm})\end{array}$ \\
\hline SBA-16 & - & 226 & 0.37 & 4.2 \\
$\mathrm{CuO} / \mathrm{SBA}-16$ & 1.77 & 114 & 0.25 & 3.6 \\
$\mathrm{~V}_{2} \mathrm{O}_{5} / \mathrm{SBA}-16$ & 2.36 & 126 & 0.28 & 3.7 \\
$\mathrm{CeO}_{2} / \mathrm{SBA}-16$ & 2.99 & 102 & 0.21 & 3.4 \\
\hline
\end{tabular}



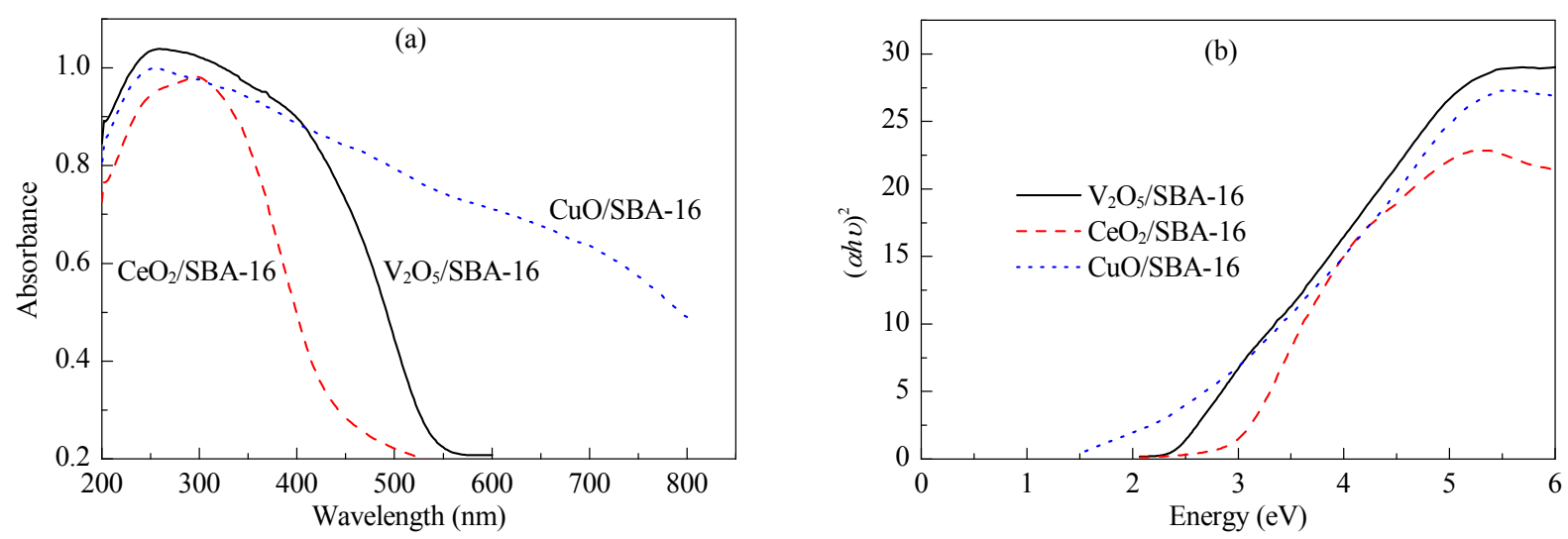

Fig. 4. Diffuse reflectance UV spectra (a) and Kubelka-Munk plots (b) of the catalysts.

tion, and the weak band at $280 \mathrm{~nm}$ was assigned to $\mathrm{Ce}^{4+} \leftarrow \mathrm{O}^{2-}$ charge transfer transitions [9]. The spectrum of CuO/SBA-16 exhibited strong absorption bands at 210-270 and $357 \mathrm{~nm}$, signifying the ligand-to-metal charge transfer transition of $\mathrm{Cu}^{2+}$ cations, and an intense band at 600-800 $\mathrm{nm}$ because of $(\mathrm{Cu}-\mathrm{O}-\mathrm{Cu})^{2+}$ clusters in a highly dispersed state. Mendes et al. [10] have observed that the broad band between 600 and 900 $\mathrm{nm}$ and the band at $\sim 350 \mathrm{~nm}$ indicate the formation of copper clusters different from bulk $\mathrm{CuO}$. Therefore, the predicted absence of active oxide crystallites as per the XRD study is supported by this observation. However, a discrepancy was noted for the $\mathrm{V}_{2} \mathrm{O}_{5} / \mathrm{SBA}-16$ sample, in which the XRD data suggested no crystalline $\mathrm{V}_{2} \mathrm{O}_{5}$ in the system. The band between 400 and $600 \mathrm{~nm}$ indicates the presence of crystalline vanadia [11]. The small size of the crystallites may be the reason for this discrepancy between experiments. The data achieved through the diffuse reflectance UV spectra were used to measure the band gap energy (Table 1), using the Kubelka-Munk plots (Fig. 4(b)).

Reducibility of the catalyst is an important aspect when we consider its efficiency as an oxidation catalyst. Pure mesoporous silica did not show any thermal conductivity detector signal corresponding to $\mathrm{H}_{2}$ consumption, confirming that the support was not reducible under the selected temperature range. The profiles obtained for the supported catalysts are shown in Fig. 5, which marked gas consumption in the temperature range $200-800{ }^{\circ} \mathrm{C}$. The supported catalysts showed a signal in the reduction profile indicating the reduction of metal oxide

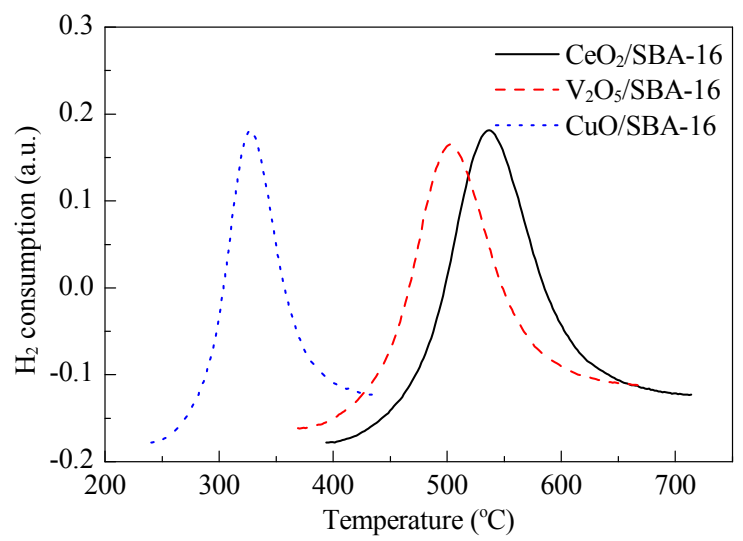

Fig. 5. $\mathrm{H}_{2}$-TPR profiles of the catalysts. species in the catalysts. The $T_{\max }$ positions (temperature corresponding to the maxima of the curve) of the $\mathrm{Cu}, \mathrm{V}$, and $\mathrm{Ce}$ mesoporous silica samples were 340,490 , and $547^{\circ} \mathrm{C}$, respectively. Copper-loaded silica is easily reducible because the peak was noticed at the lowest temperature among the three catalysts. The reducibility followed the order $\mathrm{CuO} / \mathrm{SBA}-16>$ $\mathrm{V}_{2} \mathrm{O}_{5} / \mathrm{SBA}-16>\mathrm{CeO}_{2} / \mathrm{SBA}-16$, which agrees with the order of reducibility of the active metal ions in the supported catalysts.

\subsection{CO oxidation activity of the supported catalysts}

The catalytic activity of the support and the impregnated systems is shown in Fig. 6. The CO oxidation activity of all the systems increased with increases in reaction temperature. SBA-16 catalysed $\sim 15 \%$ conversion of CO under the given experimental conditions. It is noteworthy that there is a large increase of oxidation activity when the silica was loaded with oxidation catalysts. The observed increase in activity was the highest for $\mathrm{CuO} / \mathrm{SBA}-16$ and the lowest for $\mathrm{CeO}_{2} / \mathrm{SBA}-16$. The activity was measured in terms of $T_{50}$ (temperature corresponding to $50 \%$ conversion of $\mathrm{CO}$ ) value, and the $T_{50}$ was 224 ${ }^{\circ} \mathrm{C}$ for $\mathrm{CuO} / \mathrm{SBA}-16$. As the other two systems exhibited comparatively low activities, a comparison was made in terms of $T_{10}$, which were observed at 154,181 , and $265^{\circ} \mathrm{C}$ for $\mathrm{Cu}, \mathrm{V}$, and Ce samples, respectively. We conclude that the trend in the activity depends solely on the reducibility of impregnated metal ions in the support. This fact has been reported by other re-

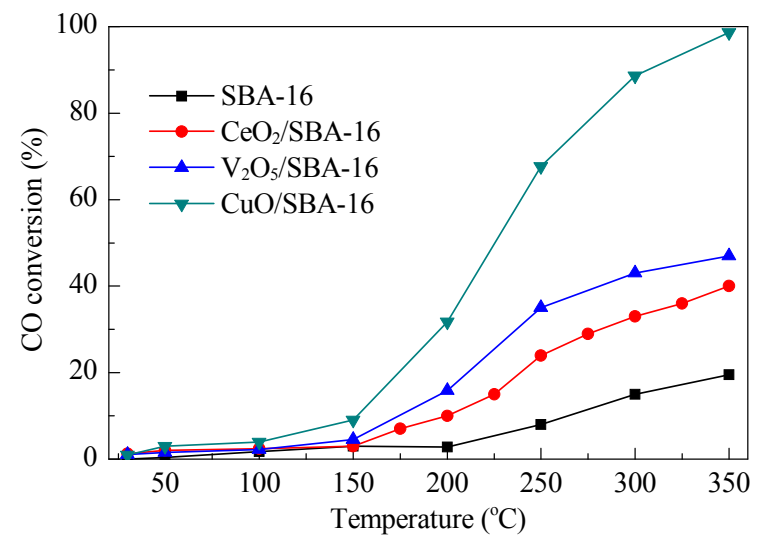

Fig. 6. Light-off curves for CO oxidation of various catalytic systems. 


\title{
Graphical Abstract
}

Chin. J. Catal., 2015, 36: 1237-1241 doi: 10.1016/S1872-2067(15)60894-4

\section{Synthesis, characterisation and activity of SBA-16 supported oxidation catalysts for Co conversion}

N. K. Renuka*, K. Anas, C. U. Aniz

University of Calicut, India; Sud-Chemie India Pvt. Limited, India
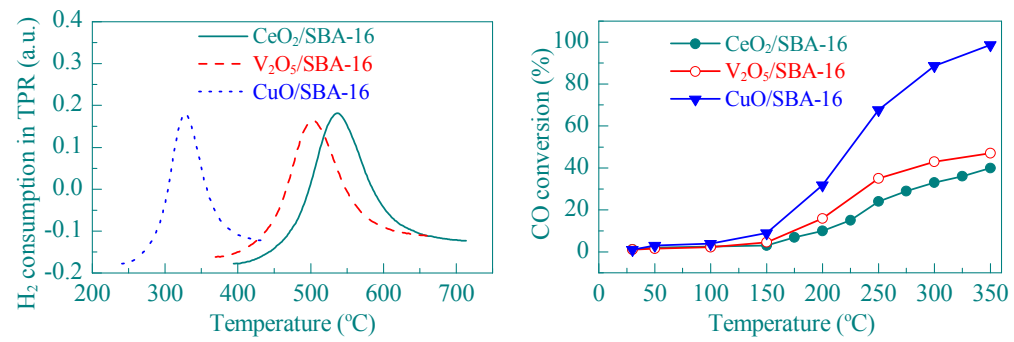

$\mathrm{V}_{2} \mathrm{O}_{5}, \mathrm{CeO}_{2}$, and $\mathrm{CuO}$ were dispersed over rice husk silica derived SBA-16, and the $\mathrm{CO}$ oxidation activity of these systems was examined. Reducibility of the catalysts was found to be decisive in the activity.

searchers also. Thus, this study supports the importance of the reducibility of the metal ion species, which renders the system effective as the oxidising agent, in deciding the activity of CO oxidation catalysts. In summary, we suggest that the CuO-incorporated system serves as an efficient catalyst for CO removal. To understand the effect of ordered mesoporous nature of the support (SBA-16) chosen in the study, CuO was supported in ordinary silica, in which the pore size was not uniform and the pore distribution covered the range 10-150 $\mathrm{nm}$. This system exhibited a $T_{50}$ value $\sim 300{ }^{\circ} \mathrm{C}$. The result indicates the advantage of ordered mesoporous SBA-16 over disordered porous silica, in deciding the activity of the supported catalysts.

\section{Conclusions}

SBA-16 synthesised from rice husk ash silica via a surfactant assisted route showed pore size of $4 \mathrm{~nm}$ and pore wall thickness of $8.9 \mathrm{~nm}$. The material served as a good support to fabricate active catalysts for $\mathrm{CO}$ oxidation. Among the three active oxidation catalysts chosen for this study $\left(\mathrm{V}_{2} \mathrm{O}_{5}, \mathrm{CeO}_{2}\right.$, and $\left.\mathrm{CuO}\right)$, the CuO-based system showed the highest activity under the given set of reaction conditions. The role of the reducibility of the catalyst in deciding the oxidation efficiency was affirmed by this study.

\section{References}

[1] Carabineiro S A C, Bogdanchikova N, Avalos-Borja M, Pestryakov A, Tavares P B, Figueiredo J L. Nano Res, 2011, 4: 180

[2] Jin M S, Park J N, Shon J K, Kim J H, Li Z H, Park Y K, Kim J M. Catal Today, 2012, 185: 183

[3] Cargnello M, Gentilini C, Montini T, Fonda E, Mehraeen S, Chi M, Herrera-Collado M, Browning N D, Polizzi S, Pasquato O L, Fornasiero P. Chem Mater, 2010, 22: 4335

[4] Ren L H, Zhang H L, Lu A H, Hao Y, Li W C. Microporous Mesoporous Mater, 2012, 158: 7

[5] Bethke G K, Kung H H. Appl Catal A, 2000, 194-195: 43

[6] Kim H Y, Lee H M, Henkelman G. J Am Chem Soc, 2012, 134: 1560

[7] Li Y Z, Yu Y, Wang J G, Song J, Li Q, Dong M D, Liu C J. Appl Catal B, 2012, 125: 189

[8] Morishige K, Tateishi N. J Chem Phys, 2003, 119: 2301

[9] Renuka N K, Praveen A K, Aniz C U. Microporous Mesoporous Mater, 2013, 169: 35

[10] Mendes F M T, Schmal M. Appl Catal A, 1997, 151: 393

[11] Gao X T, Wachs I E. J Phys Chem B, 2000, 104: 1261

\section{SBA-16负载金属氧化物催化剂合成、表征及催化CO氧化反应活性}

\author{
N. K. Renuka ${ }^{\mathrm{a}, *}$, K. Anas ${ }^{\mathrm{b}}$, C. U. Aniz ${ }^{\mathrm{b}}$ \\ a卡利卡特大学化学系, 喀拉拉邦-673635, 印度 \\ ${ }^{\mathrm{b}}$ 印度南方化学公司研发部, Binanipuram-683502, 喀拉拉邦, 印度
}

摘要: 将 $\mathrm{V}_{2} \mathrm{O}_{5}, \mathrm{CeO}_{2}$ 和 $\mathrm{CuO}$ 分散到提取自稻米壳的 $\mathrm{SBA}-16$ 上, 考察了其催化 $\mathrm{CO}$ 氧化反应活性, 并采用X射线衍射、扫描电镜、透 射电镜、程序升温还原和紫外漫反射光谱对所制催化剂进行了表征. 结果表明, 掺杂 $\mathrm{CuO}$ 的介孔氧化硅是一种有前景的催化剂, 其CO转化率可达 $98 \%$ 以上.

关键词: 稻米壳灰; 介孔氧化硅; SBA-16; 金属氧化物催化剂; 一氧化碳氧化

收稿日期: 2015-03-20. 接受日期: 2015-05-13. 出版日期: 2015-08-20.

*通讯联系人. 电话: +91-494-2407413; 传真: +91-494-2400269; 电子信箱: nkrenu@gmail.com

本文的英文电子版由Elsevier出版社在ScienceDirect上出版(http://www.sciencedirect.com/science/journal/18722067). 